\title{
The Distribution and Structure of FTS Immunoreactive Cells in the Thymus of the Mouse
}

\author{
Shigeko Fujiwara ${ }^{1}$, Hisashi KobaYASHI ${ }^{2}$ and Akira AWAYA ${ }^{2}$ \\ Department of Anatomy ${ }^{1}$, Niigata University School of Medicine, Niigata and Institute of Biological Sciences and New Product \\ Planning Department ${ }^{2}$, Mitsui Pharmaceuticals, Inc., Tokyo, Japan
}

Received June, 15, 1988

Summary. The intrathymic distributions of facteur thymique sérique (FTS) -containing cells and Ia-expressing cells were examined by a double immunofluorescence technique in $\mathrm{C} 57 \mathrm{BL} / 6$ mice of various ages.

In the thymic medulla of all the mice examined, there were both FTS-immunoreactive cells and Ia-immunoreactive cells. The former cells, epithelial in nature, extended elongate cytoplasmic processes, while the latter were connected with each other by their spiny processes. The FTS-immunoreactive epithelial cells were all Ia-negative. The FTS-immunoreactive cells and Ia-immunoreactive cells were located in close proximity to each other.

The cortex of the adult mice contained no FTS-immunoreactive epithelial cells. The cortex of the newborn and old mice, however, contained scattered FTS-immunoreactive epithelial cells with processes. FTS-immunoreactive cells in the cortex of the old mice possesed Ia-immunoreactive partner cells, while those in the cortex of newborn mice did not.

In the marginal zone of the medulla of old mice, there were several cavities bounded by a partly ciliated epithelium and containing lymphocytes. The epithelial cells lining the cavities showed intense immunofluorescence for FTS.

In addition to the epithelial cells, a certain population of round cells with thin cytoplasm lacking in discernible processes immunofluoresced for FTS. Located both in the medulla and in the cortex, these round cells were postulated to be thymocytes, the target cells of FTS, binding FTS on their cell surface.

Facteur thymique sérique (FTS) is a circulating thymic factor originally isolated from pig serum (DARDENNE et al., 1977). It has been well established that FTS from many species consists of the same amino acid sequence (PLEAU et al., 1977). FTS has been demonstrated to be produced by thymic epithelial cells (DARDENNE et al., 1974). Thymic epithelial cells were demonstrated by MONIER et al. (1980) to contain FTS in perikarya by means of an indirect immunofluorescence technique using cell cultures or imprints of the thymus. SAVINO et al. (1982) showed that the epithelial cells in the medulla contain FTS, using a monoclonal antibody. At the electron microscopic level, FTS-like immunoreactivity has been demonstrated in cytoplasmic vacuoles in cultured thymic epithelial cells (SchmiTt et al., 1980) or thymic tissue (SchmitT et al., 1982).

This report aims for a more precise demonstration of the intrathymic distribution and morphology of FTS-containing cells and its age-related changes than has been offered in previous reports. Special reference is given to the possible topographic relation of the FTS-positive cells with Ia-expressing cells, because both cells have been supposed to cooperate in the differentiation of thymocytes, and are believed to be located close to each other (SAvino et al., 1983). For this purpose, both cells were examined by the double immunofluorescence technique using a polyclonal antiserum against FTS-BSA and a monoclonal antibody against Ia antigen (I-A gene product) in cryostat sections of the thymus of $\mathrm{C} 57 \mathrm{BL} / 6$ mice. In consideration of possible age-related differences in the distribution and structure of FTS-immunoreactive cells in the thymus, specimens from mice of various ages were examined in this study.

\section{MATERIALS AND METHODS}

Animals: Normal male and female C57BL/6 mice of various ages $(1 \mathrm{~W}, 1 \mathrm{M}, 2 \mathrm{M}, 5 \mathrm{M}$ and $12 \mathrm{M})$ were used. All mice were bred and maintained in the Facilities of Comparative Medicine and Animal Experimentation of our University.

Tissue sections: Thymuses were removed from the mice under ether anesthesia and frozen in liquid 
nitrogen. Sections of $8 \mu \mathrm{m}$ thickness were made with a cryostat (Sakura CM-41, Tokyo).

Antibodies: Anti-FTS antiserum was raised in rabbits immunized with FTS coupled with bovine serum albumin in Freund's complete adjuvant. The animals were immunized with 2 or $3 \mathrm{mg}$ of FTS-BSA 8 times and antiserum was obtained 9 days after the last immunization. It was inactivated at $56^{\circ} \mathrm{C}$ for 30 min. Anti-Ia ${ }^{\mathrm{b}}$ is an IgG2a monoclonal antibody obtained commercially (Meiji Health Science, Tokyo). It reacts not only with $\mathrm{Ia}^{\mathrm{b}}$ but also with $\mathrm{Ia}^{\mathrm{k}}$ and $\mathrm{Ia}^{\mathrm{s}}$.

Fluorescence labelled antibody: Fluorescent isothiocyanate (FITC)-labelled swine anti-rabbit $\gamma$-globulin was purchased from Dakopatts (Copenhagen, Denmark). Rhodamin-labelled sheep anti-mouse IgG2a antibodies were also purchased (Serotec, Blackthorn, England).

Immunofluorescence technique: Sections of the thymus were fixed with methanol for $15 \mathrm{~min}$. They were incubated with a mixture of diluted $(1: 20)$ normal swine serum and normal sheep serum in a moist chamber for $30 \mathrm{~min}$ at room temperature. After washing three times in phosphate-buffered saline (PBS) for $3 \mathrm{~min}$, the sections were incubated with a mixture of diluted anti-FTS antiserum (1: 200) and anti-Ia ${ }^{\mathrm{b}}$ monoclonal antibody at $4^{\circ} \mathrm{C}$ overnight or at $37^{\circ} \mathrm{C}$ for $60 \mathrm{~min}$. After washing three times in PBS for $5 \mathrm{~min}$, they were incubated with a mixture of diluted FITClabelled swine anti-rabbit $\gamma$-globulin (RGG) $(1: 20)$ and rhodamine-labelled sheep anti-mouse IgG2a $\gamma$ globulin $(1: 40)$ at $37^{\circ} \mathrm{C}$ for $30 \mathrm{~min}$. After washing in PBS for 5 min three times, the sections were mounted with glycerine containing $10 \% \mathrm{PBS}$ and 1,4-diazobicyclo(2.2.2.)-octane (DABCO) $(25 \mathrm{mg} / \mathrm{ml})$. Immunofluorescence reactions were examined using an epifluorescence microscope (Olympus, Tokyo).

Blocking test: To examine the specificity of the immunofluorescence reaction, adjacent sections were incubated with the primary antiserum mixed with 5 $\mu \mathrm{g} / \mathrm{ml}$ of synthesized FTS. Other procedures were the same as described above.

Poststaining with hematoxylin and eosin: Some sections, after examining for immunofluorescence, were stained with hematoxylin and eosin and observed under a light microscope.

\section{RESULTS}

\section{Adult C57BL/6 mice}

FTS-containing cells were detected by the indirect immunofluorescence technique using rabbit anti-FTS and FITC-labelled swine anti-RGG. At first, normal adult C57BL mice were examined as the standard for further studies.

The major component showing FTS-immunofluorescence was stellate cells with strong fluorescence in perikarya extending FTS-positive cytoplasmic processes. They usually appeared in larger or smaller cell groups. Cells of this type were recognized only in the thymic medulla in normal adult mice (Fig. 1). Observation at higher magnification revealed the fluorescence of a distinct granular pattern both in perikarya and cytoplasmic processes (Fig. 2).

Another type of immunoreactive cells were round cells of a size corresponding to that of large lymphocytes. No processes could be recognized. They were scattered not only in the medulla but also in the cortex (Fig. 1). Their fluorescence was weaker than that in the FTS-containing epithelial cells, and careful fluorescent microscopic observation suggested that the immunoreactivity apparently was restricted to the cell surface. Light microscopic observation after hematoxylin-eosin staining revealed that the cell consisted of a large round nucleus with a moderate amount of chromatin and thin cytoplasm.

There was no change in the localization of FTSimmunoreactive cells in the thymus from 1 month to 5 months of age.

In both two types of cells, the fluorescence was completely inhibited by the blocking test in which synthesized FTS $(5 \mu \mathrm{g} / \mathrm{ml})$ was mixed with the primary antiserum.

Immunoreactivity for I-A gene products $\left(\mathrm{Ia}^{\mathrm{b}}\right)$ was detected in cells plentifully dispersed in the medulla (Fig. 3). These were angular, polygonal cells with rather spiny processes, by which they were connected with each other. Some of these Ia-immunoreactive cells in the medulla and isolated cells in the cortex were large cells with a strong fluorescence of coarse granular pattern. The fluorescence of the latter cells was not specific, as the cells fluoresced also in the control test without the primary antibody. Moreover, they had the autofluorescence of lipofustin. These large Ia-immunoreactive cells therefore were identified as macrophages. Such cells increased in number with age. In older mice, the macrophages showed stronger autofluorescence of lipofustin, and were more easily distinguished from other Ia-immunoreactive cells than in younger animals.

Careful observation in doubly immunostained sections indicated that the FTS-immunopositive cells were Ia-immunonegative (Figs. 1, 3). The FTS-immunoreactive epithelial cells were located in close proximity to Ia-immunoreactive cells. 

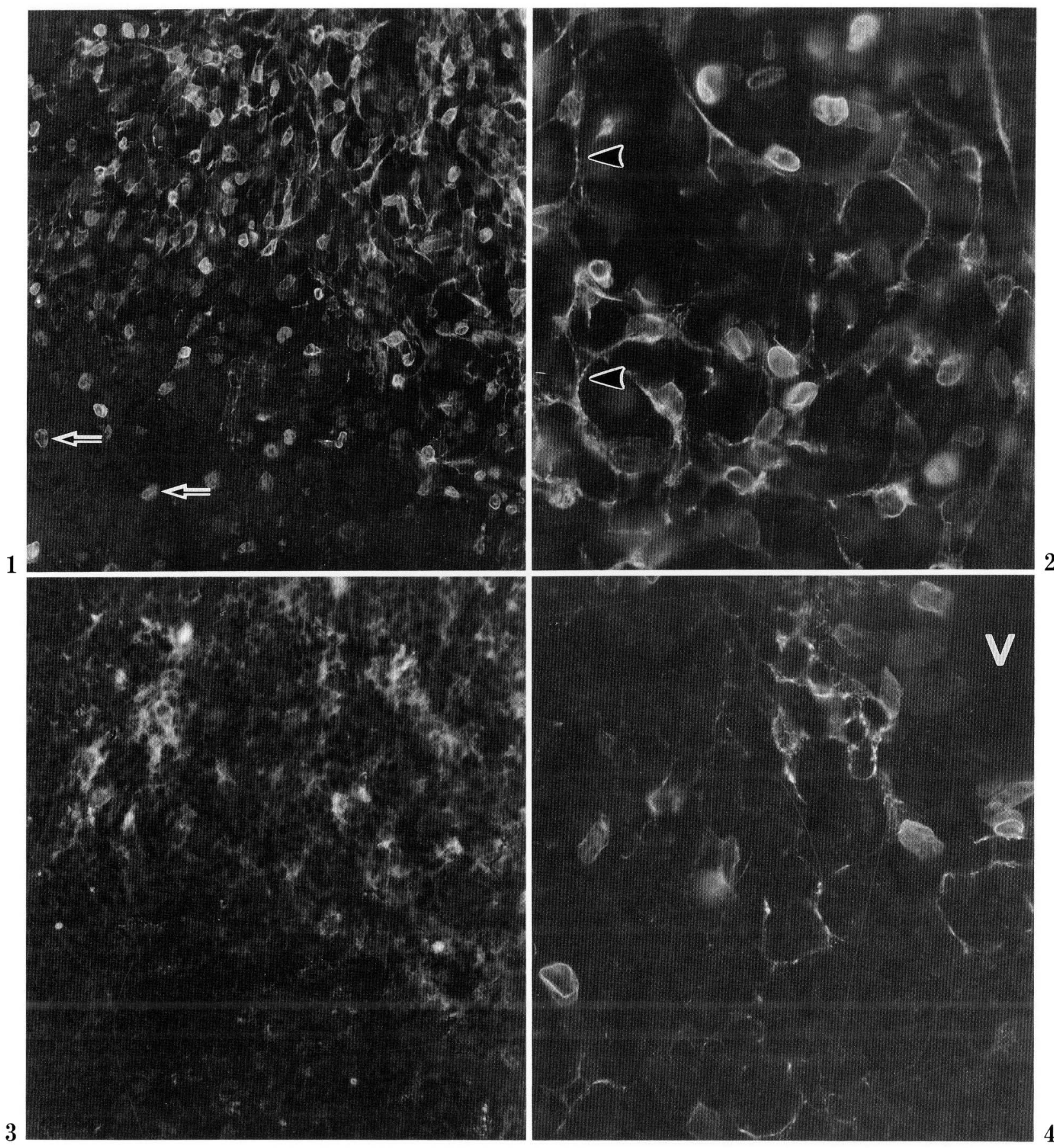

Fig. 1. FTS-immunoreactive cells in the thymus of a 2 -month-old C57BL/6 mouse. In the medulla (upper), there are many FTS-immunoreactive epithelial cells with slender cytoplasmic processes. Both in the medulla and the cortex (lower left) there are some scattered round cells with weak FTS-fluorescence (arrows). $\times 320$

Fig. 2. FTS-immunoreactive epithelial cells in the medulla of a 2-month-old C57BL/6 mouse. Note the granular pattern of FTS-fluorescence along the cytoplasmic processes (arrowheads). Round cells with weak FTS-fluorescence are also seen. $\times 760$

Fig. 3. Ia-immunoreactive cells in the same section as shown in Figure 1. There are many Ia-immunopositive cells in the medulla (upper right). $\times 320$

Fig. 4. FTS-immunoreactive cells in the thymus of a 1-week-old C57BL/6 mouse. Some FTS-containing cells are seen around the vein $(V)$ in the cortex. They extend long processes immunoreactive for FTS between FTS-negative thymocytes. $\times 760$ 

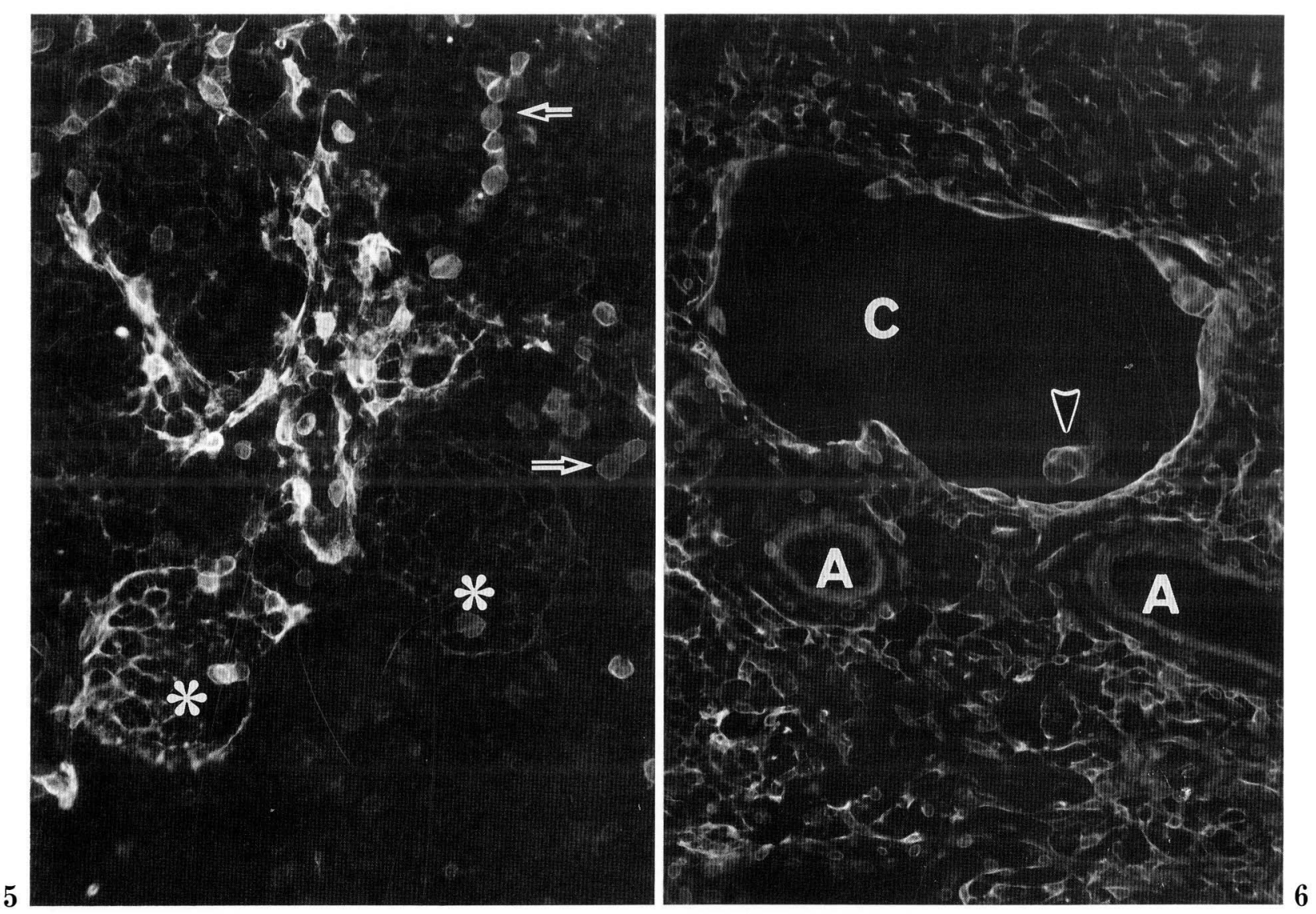

Fig. 5. FTS-immunoreactive cells in the thymus of a 12 -month-old C57BL/6 mouse. In the medulla (upper) there are strongly FTS-positive cells with FTS-positive cytoplasmic processes. In the cortex (lower) there are two honeycomb structures (asterisk) wrapping around the FTS-negative thymocytes. Both in the medulla and the cortex there are round cells with weak FTS-fluorescence (arrows). $\times 400$

Fig. 6. The medulla in the thymus of a 12-month-old C57BL/6 mouse. A cavity $(C)$ is bounded by FTSimmunoreactive epithelial cells. A part of the bounding epithelium protrudes into the cavity (arrowhead). $A$ artery. $\times 320$

\section{Juvenile C57BL/6 mice}

In the thymus of 1-week-old mice, the distribution pattern of FTS-immunoreactivity was similar to that in the adult mice. The FTS-immunoreactive epithelial cells with long cytoplasmic processes differed slightly in distribution from the corresponding cells in the adult mice: immunofluorescent cells with fine elongated cytoplasmic processes were scattered also in the cortex (Fig. 4). Immunofluorescent cells located around blood capillaries in the cortex often extended long cytoplasmic processes. These cytoplasmic processes stretched for more than $50 \mu \mathrm{m}$. FTS-immunoreactive round cells showed a distribution and structure similar to those in the adult mice.

Ia-immunoreactive cells were detected only in the medulla, as in the adult animals. The FTS-immunoreactive epithelial cells were in close proximity to the Ia-immunoreactive cells in the medulla, but in the cortex they were isolated from the Ia-immunoreactive cells. There were very few macrophages with coarse granular fluorescence assessed by anti- $\mathrm{Ia}^{\mathrm{b}}$.

\section{Old C57BL/6 mice}

In the thymus of 12-month-old mice, two kinds of FTS-immunoreactive cells were also identified. The cells with stronger fluorescence were detected mainly in the medulla as in the adult and juvenile mice. The distribution of this type of cells was slightly different from that in the adult mice. In the cortex there were many cells in small groups strongly fluorescencing in the cell bodies and processes. Also in the cortex of 
old mice, honeycomb-like structures (Fig. 5) of fine extensive cytoplasmic processes wrapping several thymocytes were found.

FTS-immunoreactive round cells showed a distribution similar to that in the adult mice, with only exception being that they sometimes appeared in groups of two or several cells (Fig. 5).

Several cavities containing round cells were found in the marginal zone of the medulla. The lining epithelial cells of the cavities showed intense immunofluorescence for FTS (Fig. 6). A few of the round cells in the cavities weakly fluoresced. Hematoxylin-eosin staining of the same section, after being observed for immunofluorescence, revealed that the round cells in the cavities were lymphocytes and that the lining epithelial cells were partly ciliated. The cavities structually resembled the "cystic cavities" described by KHOSLA and OvALLE (1986).

Ia-immunoreactive cells were found, in contrast to the findings in younger animals, in the cortex in addition to the medulla. The Ia-immunoreactive cells in the medulla were similar to those in the normal adult mice, and were connected with each other by their short processes. The Ia-immunoreactive cells in the cortex were scattered and located in association with the FTS-immunoreactive cells. In this respect, FTS-immunoreacting cells in the cortex of the old mice were different from those in the cortex of the newborn mice. There were many macrophages with autofluorescence which were strongly Ia-immunoreactive.

\section{DISCUSSION}

\section{Age-related changes in FTS-immunoreactive cells}

SAVINO et al. (1982) reported that the FTS-immunoreactive cells were thymic epithelial cells in the medulla. The present study confirms that the main component of FTS-containing cells is represented by epithelial cells in the medulla. We examined the distribution of FTS-containing cells in the thymus of various ages and found slight changes in their distribution. In the adult mice 1-5 months of age, the FTS-immunoreactive epithelial cells were found only in the thymic medulla. In 1-week-old mice, some FTS-immunoreactive epithelial cells were found also in the cortex. In the 12-month-old mice, a few grouped FTS-immunoreactive epithelial cells were detected in the cortex. The serum level of FTS and age related changes in the number of FTS-immunoreactive cells in normal C57BL mice and autoimmune NZB mice were reported by SAVINO et al. (1983). Both of these decreased rapidly after 6 months of age in normal C57BL mice and much earlier in NZB mice. In our investigation using C57BL mice, the FTS-immunoreactive epithelial cells per one longitudinal section of the thymus were by far greater in number than those found by SAVINO et al. (1983) and the number of the cells did not decrease noticeably in normal C57BL mice until 12 months of age.

\section{Relationship of Ia-immunofluorescent cells with FTS-immunoreactive cells}

In adult mice, Ia-immunoreactive cells were always found in close proximity to the FTS-immunoreactive epithelial cells. In one-week-old mice, no Ia-immunoreactive cells were found in the cortex and, therefore, the FTS-immunoreactive cells in the cortex were isolated from Ia-immunoreactive cells. In the 12month-old mice, on the contrary, Ia-immunoreactive cells were located in association with the FTS-immunoreactive cells in the cortex as in the medulla of the thymus in any ages of the mice examined. In this respect, FTS-immunoreactive cells in the cortex of the old mice were different from those in the cortex of the newborn mice. Thymuses are involuting in the old mice. The groups of FTS-immunoreactive cells in the thymic cortex of old mice may presumably have been in the medulla that has shrunken and is then incorporated in the cortex. All the FTS-immunoreactive epithelial cells were regularly located in association with Ia-immunoreactive cells. Only in the thymic cortex of the newborn mice were they isolated from the Ia-immunoreactive cells. According to this finding, thymocytes may not have fully differentiated with regard to the Ia-restriction as this life stage, at least in the cortex.

\section{Miscellaneous findings}

Cavities structually resembling the "cystic cavities" described by KHOSLA and OvalLE (1986) were found in the marginal zone of the thymic medulla in the old mice, and lining epithelial cells were strongly FTSimmunoreactive. The role of these cavities is unknown. Considering the fact that the lining epithelial cells contain FTS, the cavities might be concerned with the differentiation of thymocytes.

The role of the honeycomb-like structure of FTSimmunoreactive cytoplasmic processes detected in the cortex of the old mice that wrapped around the thymocytes is not clear.

\section{FTS-immunopositive cytoplasmic granules}

The mechanism of secretion in the thymic epithe- 
lial cells has been studied by electron microscopy (Hoshino, 1962, SchmitT et al., 1982, NABARRA and ANDRIANALISON, 1987), and in vitro (DARDENNE et al., 1974; SAVINO and DARDENNE, 1986). The large round vesicles identified by electron microscopy are believed to store thymulin (zinc-binding FTS) and are presumed to release it by exocytosis (NABARRA and ANDRIANARISON, 1987). Examination of the thymic epithelial cells under the electron microscope showed that large round vesicles are easily found in the epithelial cells of the surface of the thymus and the perivascular spaces and in the medullary epithelial cells. These vesicles were 0.7 to $2.2 \mu \mathrm{m}$ in diameter and were located not only in the cell bodies but also in the elongated cytoplasmic processes between thymocytes. Observation of the FTS-immunoreactive epithelial cells at higher magnification revealed that the fluorescence showed a distinct granular pattern both in perikarya and cytoplasmic processes. The FTS-immunoreactive granules seem to correspond to the vesicles identified by electron microscopy.

\section{Possibility of FTS-immunoreactive round cells to be thymocytes}

In addition to the FTS-immunoreactive epithelial cells in the medulla, we found that scattered round cells with thin cytoplasm were immunoreactive for FTS both in the medulla and the cortex. Their fluorescence was weaker than that of the epithelial cells. A few of the lymphocytes in the cavities in the old mice also immunofluoresced for FTS. The fluorescence pattern of these round cells was similar to the immunofluorescence for surface immunoglobulin in the living B-lymphocytes. Poststaining with hematoxylin and eosin showed that they could not be distinguished from other FTS-negative thymocytes. We would like to consider that they might be target thymocytes that bind FTS on the recepter of cell surface.

Acknowledgements. The authors wish to extend thier deep appreciation to Professor T. FujITA and Dr. T. IWANAGA (Department of Anatomy, Niigata University Medical School) for their kind instructions and critical discussions.

\section{REFERENCES}

Dardenne, M., M. Papirnik, J. F. Bach and O. Stut MAN: Studies on thymus products. III Epithelial origin of the serum thymic factor. Immunology 27:299-304 (1974).

Dardenne, M., J. M. Pleau, N. K. Man and J. F. Bach : Structual study of a circulating thymic factor: a peptide isolated from pig serum. II. Isolation and purification. J. Biol. Chem. 252: 8040-8044 (1977).

Hoshino, T.: The fine structure of ciliated vesiclecontaining reticular cells in the mouse thymus. Exp. Cell Res. 27: 615-617 (1962).

Khosla, S. and W. K. Ovalle: Morphology and distribution of cysitic cavities in the normal murine thymus. Cell Tiss. Res. 246: 531-542 (1986).

Monier, J. C., M. Daldesnne, J. M. Pleau, D. Schmitt, P. DeschauX and J. F. BACH: Characterization of facteur thymique sérique (FTS) in the thymus. I. Fixation of anti-FTS antibodies on thymic reticuloepithelial cells. Clin. Exp. Immunol. 42: 470-476 (1980).

Nabarra, B. and I. Andrianarison: Pattern of secretion in thymic epithelial cells: Ultrastructual Studies of the effect of blockage at various levels. Cell Tiss. Res. 249: 171-178 (1987).

Pleau, J. M., M. Daldenne, Y. Blouquit and J. F. BACH : Structural study of a circulating thymic factor: a peptide isolated from pig serum. II. Amino acid sequence. J. Biol. Chem. 252: 8045-8047 (1977).

Savino, W., M. Dardenne, M. Rapiernik and J. F. BACH: Thymic hormone-containing cells. Characlerization and localization of serum thymic factor in young mouse studied by monoclonel antibodies. J. Exp. Med. 156: 628-633 (1982).

Savino, W., M. Dardenne and J. F. Bach: Thymic hormone containing cells. II. Evolution of cells containing the serum thymic factor (FTS or thymulin) in normal and autoimmune mice, as revealed by anti-FTS monoclonal antibodies. Relationship with Ia bearing cells. Clin. Exp. Immunol. 52: 1-6 (1983).

Savino, W. and M. Dardenne: Thymic hormonecontaining cells. VI. Immunohistlogic evidence for the simultaneous presence of thymulin, thymopoietin and thymosin $\alpha_{1}$ in normal and pathological human thymuses. Eur. J. Immunol. 14: 987-991 (1984).

Schmitt, D., J. C. Monier, M. Dardenne, J. M. Plaeu, P. Deschaux and J. F. BACH: Cytoplasmic localization of FTS (facteur thymique sérique) in thymic epithelial cells. An immunoelectron microscopical study. Thymus 2: 177-186 (1980).

Schmitt, D., J. C. Monier, M. Dardenne, J. M. Pleau and J. F. BACH: Localization of FTS (facteur thymique sérique) in the thymus of normal and autoimmune mice. Thymus $4: 221-231$ (1982).

Dr. Shigeko FUJWARA
Laboratory of Immunology
Department of Medical Zoology
Niigata University School of Medicine
Asahimachi, Niigata
951 Japan
藤 原 成子
951 新潟市旭町通 1
新潟大学医学部
医動物学教室
Laboratory of Immunology Department of Medical Zoology Niigata University School of Medicine Asahimachi, Niigata

J1 Japan 951 新潟市旭町通 医動物学教室 